\title{
SISTEM PENDUKUNG KEPUTUSAN PEMILIHAN SISWA TERBAIK MENGGUNAKAN METODE WP (WEIGHTED PRODUCT) STUDI KASUS DI SMP MA'ARIF NU BENJENG
}

\author{
Slamet Budiono \\ SMP Ma'arif NU Benjeng \\ email : Idubbudi16@gmail.com
}

\begin{abstract}
ABSTRAK
Pemilihan siswa terbaik adalah salah satu langkah penting bagi sekolah menengah pertama atas baik negeri maupun swasta untuk mempersiapkan siswa yang dapat menjadi andalan bagi sekolah dan panutan bagi siswa lain dalam berprestasi. Dalam meningkatkan prestasi siswa SMP Ma'arif NU Benjeng memberikan kesempatan kepada siswa menjadi siswa terbaik untuk mengikuti perlombaan. Untuk membantu menentukan siswa yang layak untuk direkomendasikan dalam mengikuti perlombaan maka diperlukan sebuah sistem pendukung keputusan.

Pada penelitian ini membuat sistem yang dapat memberikan rekomendasi siswa berdasarkan kriteria-kriteria yang telah ditentukan dengan menggunakan metode WP (Weighted Product). Dari beberapa kriteria yang digunakan akan diberikan nilai bobot yang berbeda-beda, kemudian dilakukan proses perangkingan yang menentukan alternatif terbaik yang terpilih untuk direkomendasikan dalam mengikuti perlombaan.
\end{abstract}

Kata Kunci : Sistem Pendukung Keputusan, Siswa Terbaik, Lomba, Weighted Product

\section{LATAR BELAKANG}

SMP Ma'arif NU Benjeng memperoleh banyak prestasi dalam bidang akademik maupun non akademik di tingkat kota, provinsi bahkan nasional. Prestasi yang pernah diraih dalam 2 tahun terakhir yaitu juara 2 pagar nusa se kabupaten gresik tahun 2016, juara 2 pagar nusa se provinsi jatim tahun 2017 dan juara 3 pelajar teladan LP Ma'arif NU Gresik. Perolehan prestasi tersebut tidak lepas dari partisipasi para siswa. Pemilihan siswa terbaik merupakan langkah penting bagi sekolah untuk mempersiapkan siswa yang dapat menjadi andalan bagi sekolah dan panutan bagi siswa lain dalam berprestasi.

Proses seleksi pemilihan siswa terbaik pada SMP Ma'arif NU Benjeng dilakukan dengan beberapa tahap yaitu siswa ditunjuk langsung oleh guru yang sudah disepakati oleh dewan guru dengan acuan berdasarkan nilai raport tertinggi, kemudian siswa akan diberi bimbingan tersendiri seperti menjawab soal-soal pelajar teladan tahun sebelumnya. Pengambilan keputusan tersebut dirasa kurang efektif karena ada kemungkinan siswa mempunyai nilai raport yang sama sehingga mengakibatkan sulitnya membandingkan siswa yang layak untuk menjadi siswa terbaik.

Penyelesaian permasalahan seleksi pemilihan siswa terbaik yang hanya berdasarkan nilai raport tertinggi siswa, dapat dilakukan dengan membuat sistem pendukung keputusan pemilihan siswa terbaik dengan menggunakan metode WP dengan menambahkan beberapa kriteria, yaitu nilai rata-rata raport siswa, absensi, ekstra kurikuler dan perilaku. 
INDEXIA: Informatic and Computational Intelegent Journal

Slamet Budiono

Sistem Pendukung Keputusan Pemilihan Siswa Terbaik Menggunakan Metode Wp (Weighted Product) Studi Kasus Di Smp Ma'arif Nu Benjeng

Metode WP ini dipilih karena metode ini menggunakan kriteria dan bobot dari masing-masing kriteria yang kemudian diolah untuk menentukan pilihan alternatif yang hasilnya berurutan berdasarkan prioritasnya.

Penelitian yang dilakukan oleh Ummu Ni'Matullilah (2011) yang judul Sistem Pendukung Keputusan Penentuan Lokasi Pertokoan Yang Strategis Menggunakan Metode WP, pada penelitian ini menunjukkan bahwa metode WP menghasilkan penilaian yang memiliki obyektifitas tinggi. dan dapat membantu pengambil keputusan menentukan lokasi pertokoan yang strategis. Berdasarkan penelitian tersebut, penelitian ini dibuat untuk memberikan rekomendasi bagi guru dalam pengambilan keputusan siswa terbaik dapat dilakukan secara cepat, tepat dan akurat. Untuk menyelesaikan permasalahan yang ada maka judul skripsi ini "SISTEM PENDUKUNG KEPUTUSAN PEMILIHAN SISWA TERBAIK MENGGUNAKAN METODE WP ( WEIGHTED PRODUCT ) STUDI KASUS DI SMP MA'ARIF NU BENJENG".

\section{LANDASAN TEORI}

\subsection{Sistem Pendukung Keputusan \\ 2.1.1 Pengertian Sistem Pendukung Keputusan}

Sistem pendukung keputusan (decision support system/DSS) adalah sistem berbasis komputer yang digunakan oleh manager atau sekelompok manager pada setiap level organisasi dalam membuat keputusan dalam menyelesaikan masalah semi terstruktur (Yakub, 2012).

Menurut Kusrini 2007 sistem pendukung keputusan merupakan sistem informasi interaktif yang menyediakan informasi, pemodelan dan pemanipulasian data. Sistem itu digunakan untuk pengambilan keputusan dalam situasi semi terstruktur dan situasi tidak terstruktur, dimana tidak seorangpun tahu secara pasti bagaimana keputusan seharusnya dibuat.

Jadi sistem pendukung keputusan merupakan suatu alternatif yang mendukung keputusan dalam proses pengambilan keputusan melalui alternatifalternatif yang diperoleh dari hasil pengolahan data, informasi dan rancang model.

\subsection{Weighted Product Model (WPM)}

Metode WP merupakan salah satu dari beberapa metode MADM (Multi Atribute Decision Making). Metode MADM merupakan metode pengambilan keputusan yang didasarkan pada beberapa atribut. Konsep permasalahannya adalah mengevaluasi $\mathrm{m}$ alternatif $\mathrm{Ai}(\mathrm{i}=1,2, \ldots, \mathrm{m})$ terhadap sekumpulan atribut atau kriteria $\mathrm{Cj}$ $(j=1,2, \ldots, n)$, dimana setiap atribut tidak saling bergantung satu dengan yang lainnya. Metode ini mengharuskan pembuat keputusan menentukan bobot bagi setiap atribut (Yoon,1989).

Adapun langkah - langkah penyelesaian dalam menggunakannya adalah :

1. Menentukan kriteria-kriteria yang akan dijadikan acuan dalam pengambilan keputusan, yaitu $\mathrm{Cj}$

2. Menentukan nilai bobot di setiap kriteria

3. Menghitung perbaikan bobot preferensi sehingga total bobot preferensi $\sum_{w j}=1$ menggunakan rumus : 
INDEXIA: Informatic and Computational Intelegent Journal

Slamet Budiono

Sistem Pendukung Keputusan Pemilihan Siswa Terbaik Menggunakan Metode Wp (Weighted Product) Studi Kasus Di Smp Ma'arif Nu Benjeng

$W_{j}=\frac{W_{j}}{\sum_{w} j} \ldots \ldots \ldots \ldots \ldots \ldots . . . . .$. persamaan 2.1

4. Menghitung nilai vektor $S$ berdasarkan persamaan

$S_{i}=\prod_{j}^{n}=1 X_{i j}^{w j} \ldots \ldots$ persamaan 2.2

dengan $\mathrm{i}=1,2, \ldots, \mathrm{m}$, dimana :

$\mathrm{S}=$ menyatakan preferensi alternatif,

$\mathrm{x}=$ menyatakan nilai kriteria,

$\mathrm{w}=$ menyatakan bobot kriteria,

$\mathrm{n}$ = menyatakan banyaknya kriteria

5. Menghitung perangkingan atau nilai $\mathrm{V}$ dengan persamaan :

$V_{i}=\frac{\prod_{j}^{n}=1 X_{i j}^{w j}}{\prod_{j}^{n}=1\left(X_{j} * w j\right.} \ldots \ldots \ldots$ persamaan 2.3

dimana :

V : Preferensi alternatif,

$\mathrm{x}$ : Nilai kriteria,

w : Bobot kriteria

6. Ditemukan urutan alternatif terbaik yang menjadi keputusan.

\section{ANALISIS DAN PERANCANGAN SISTEM}

\subsection{Analisis Sistem}

Dalam Pemilihan siswa terbaik di SMP Ma'arif NU Benjeng dalam pengambilan keputusan dilakukan dengan cara rekomendasi secara subyektif oleh guru. Pemilihan siswa terbaik di SMP Ma'arif NU Benjeng saat ini hanya berdasarkan pada satu kriteria saja yaitu nilai tertinggi pada rapor. Oleh sebab itu dalam pemilihan siswa terbaik selanjutnya akan digunakan beberapa kriteria, kemudian penilaian tersebut akan dikalkulasi secara keseluruhan. Maka penyelesaian masalah tersebut dapat dilakukan dengan merancang sebuah sistem pendukung keputusan siswa terbaik dengan menggunakan metode Weighted Product (WP). Sistem ini nantinya dibuat untuk memberikan rekomendasi bagi guru dalam pengambilan keputusan pemilihan siswa terbaik di SMP Ma'arif NU Benjeng, sehingga proses pengambilan keputusan pemilihan siswa terbaik dapat dilakukan secara cepat, tepat dan akurat.

Adapun permasalahan di SMP Ma'arif NU Benjeng yang dihadapi saat ini adalah sulitnya dalam pengambilan keputusan pengambilan keputusan siswa terbaik di SMP Ma'arif NU Benjeng untuk direkomendasikan dalam mengikuti perlombaan pelajar teladan LP Ma'arif NU Gresik.

\subsection{Hasil Analisis}

Dari tahap analisis dapat diketahui kendala yang terjadi, sistem yang akan dibangun nantinya diharapkan dapat memberikan rekomendasi siswa yang berkompeten yang akan mengikuti perlombaan pelajar teladan, sehingga proses pengambilan keputusan pemilihan siswa terbaik dapat dilakukan secara cepat, tepat dan akurat. Dimana dalam prosesnya nanti terdapat dua entitas yaitu bagian tata usaha yang bertugas sebagai entitas aktif yang bertanggung jawab terhadap pengolahan data siswa dan entitas yang kedua adalah kepala sekolah yang berfungsi untuk menerima laporan hasil perhitungan kompetensi siswa. Untuk dapat melakukan proses perhitungan pertimbangan sebagai bahan acuan pengambilan keputusan, maka perlu ditentukan beberapa variabel penilaian sebagai dasar perhitungan. Variabel yang digunakan meliputi 4 faktor yaitu absensi, nilai ekstrakulikuler, nilai pelajaran umum dan perilaku. Dari 
Sistem Pendukung Keputusan Pemilihan Siswa Terbaik Menggunakan Metode Wp (Weighted Product) Studi Kasus Di Smp Ma'arif Nu Benjeng

keempat faktor variabel tersebut kemudian ditentukan rating kepentingan atau bobot dari setiap variabel masingmasing rekomendasi dari peneliti dan disetujui oleh pihak sekolah. Berikut adalah presentase bobot setiap kriteria yang dijadikan sebagai acuan dalam proses pemilihan siswa terbaik dapat dilihat pada Tabel 3.1

Tabel 3.1 Bobot Preferensi Kriteria

\begin{tabular}{|c|l|c|}
\hline No & Variabel / Kriteria & Nilai \\
\hline 1 & Mata Pelajaran Umum & 5 \\
\hline 2 & Absensi & 3 \\
\hline 3 & Ekstra Kurikuler & 4 \\
\hline 4 & Perilaku & 4 \\
\hline
\end{tabular}

\subsubsection{Diagram Alir Utama}

Dalam diagram alir utama ini digambarkan algoritma secara umum untuk semua proses yang ada dalam sebuah Sistem Pendukung Keputusan. Proses diawali dengan pengisian form penilaian oleh TU, kemudian dilakukan proses perhitungan oleh sistem untuk proses pemilihan siswa terbaik. Berikut alur dari diagram utama dapat dilihat pada Gambar 3.1

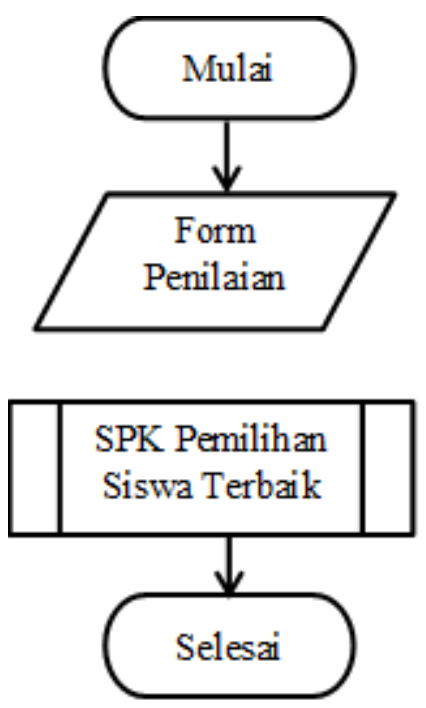

Gambar 3.1 Alur Utama Sistem Pendukung Keputusan

\subsubsection{Diagram Alir Sistem Pendukung Keputusan Metode WP}

Diagram alir ini berfungsi untuk menggambarkan alur algoritma serta proses yang digunakan pada sistem pendukung keputusan pemilihan siswa terbaik dengan menggunakan metode Weighted Product (WP) yang berfungsi untuk menghitung besaran nilai dari variabel pendukung yang ada. Berikut adalah diagram alir menggunakan metode Weighted Product (WP) pada Gambar 3.2

\begin{tabular}{l|l|} 
Admin / TU & Kepala Sekolah \\
\hline
\end{tabular}


Sistem Pendukung Keputusan Pemilihan Siswa Terbaik Menggunakan Metode Wp (Weighted Product) Studi

Kasus Di Smp Ma'arif Nu Benjeng

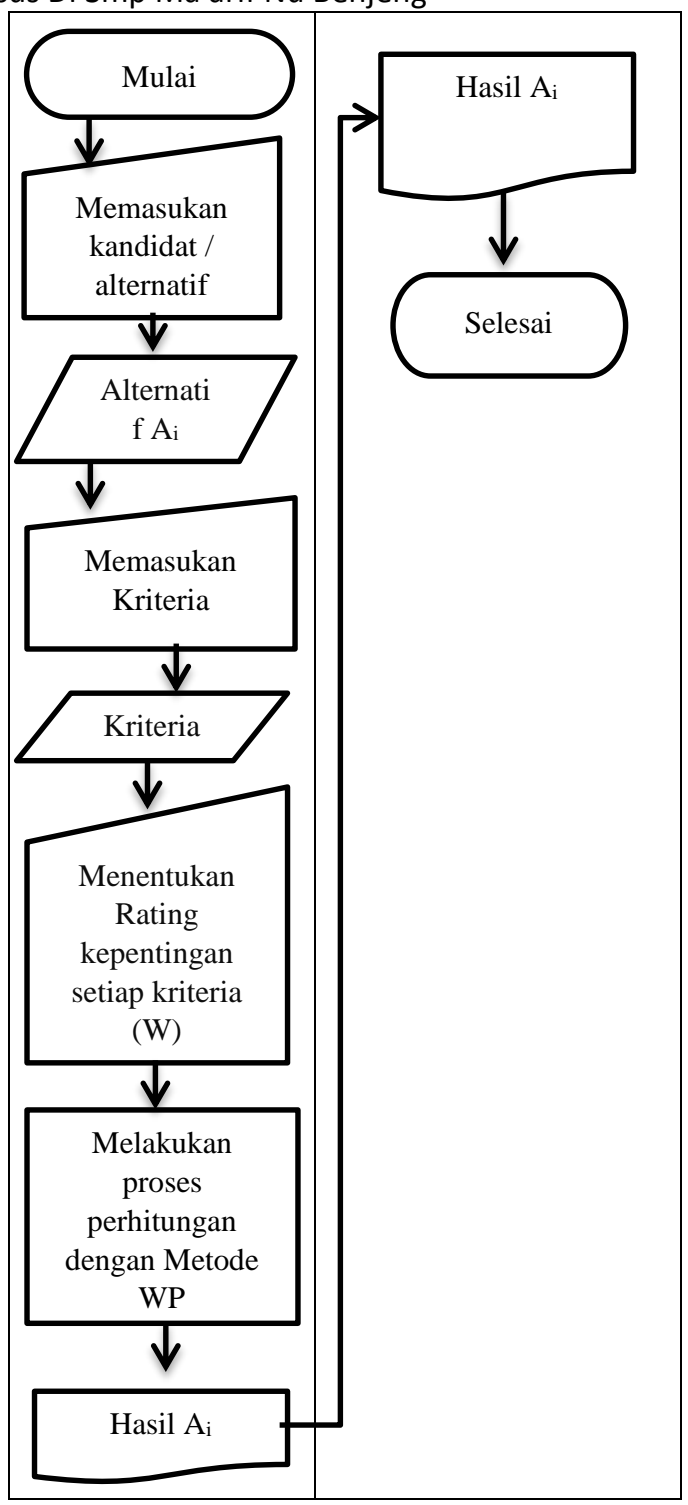

Gambar 3.2 Diagram Alir SPK dengan Metode WP

\section{IMPLEMENTASI DAN PENGUJIAN SISTEM}

\subsection{Implementasi}

Implementasi ini merupakan penerapan aplikasi dari analisa dan rancangan sistem yang telah dibuat sebelumnya. Dengan adanya implementasi ini dapat dipahami jalannya suatu sistem pendukung keputusan pemilihan siswa terbaik dengan metode WP (Studi kasus SMP Ma'arif NU Benjeng). Pada dasarnya implementasi dari sistem ini terdapat 4 macam antara lain : penilaian bobot kriteria, penilaian kompetensi siswa, normalisasi nilai kompetensi \& perankingan siswa.

\subsection{Pengujian Sistem}

Hasil pengujian sistem yang telah dibangun merupakan proses pengujian fungsi dari antarmuka yang telah dibuat apakah sudah sesuai atau belum dengan yang diharapkan.

\subsubsection{Halaman Login}

Halaman login adalah halaman yang ditampilkan sebelum pengguna dapat menggunakan aplikasi. Pada halaman ini terdapat dua form yang harus di isi dengan benar agar bisa masuk kedalam aplikasi. Halaman login dapat dilihat pada Gambar 4.1

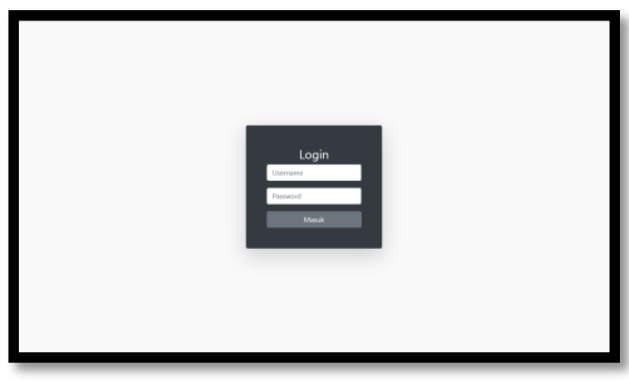

Gambar 4.1 Halaman Login

\subsubsection{Halaman Data Kriteria}

Halaman data kriteria terdiri dari nama kriteria, jenis kriteria dan bobot kriteria. User admin dapat menambahkan data kriteria dengan mengisi data kriteria pada menu tombol tambah data. Nama kriteria diisikan dengan nama kriteria apa yang akan dijadikan acuan penilaian kompetensi siswa. Jenis kriteria ada dua yaitu benefit dan cost, kriteria berjenis benefit jika nilai maksimal adalah nilai terbaik dan berjenis cost jika nilai minimal adalah nilai terbaik berikut dapat dilihat pada Gambar 4.2 
Sistem Pendukung Keputusan Pemilihan Siswa Terbaik Menggunakan Metode Wp (Weighted Product) Studi

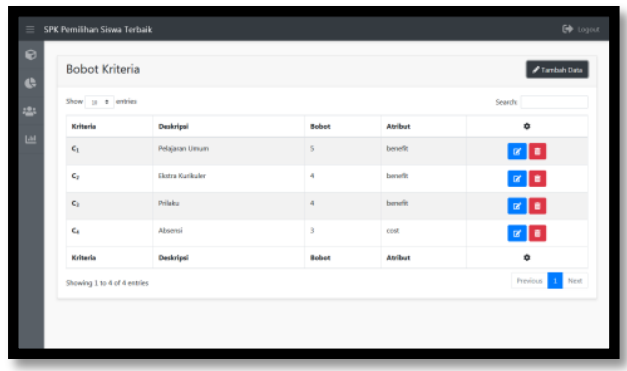

Gambar 4.2 Halaman Data Kriteria

\subsubsection{Halaman Data Alternatif}

Halaman data alternatif berisi data nilai kompetensi siswa setiap kriteria masingmasing siswa. User admin dapat menambahkan data nilai kompetensi siswa dengan mengisi data nilai kompetensi siswa pada menu tombol tambah data berikut dapat dilihat pada

\section{Gambar 4.3}

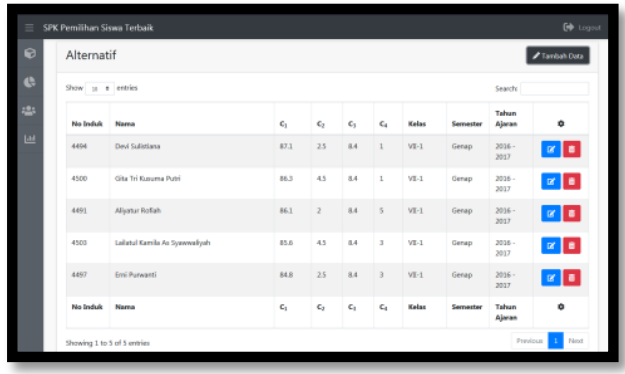

Gambar 4.3 Halaman Data Alternatif

\subsubsection{Halaman Normalisasi \& Prangkingan}

Halaman normalisasi dan prangkingan berisi data hasil perhitungan normalisasi nilai kompetensi siswa berdasarkan jenis masing-masing kriteria dan merupakan output terakhir dari perhitungan. User admin dapat memilih opsi data kelas, semester dan tahun ajaran sebelum melakukan analisi perhitugan kompetensi siswa berikut dapat dilihat pada Gambar 4.4

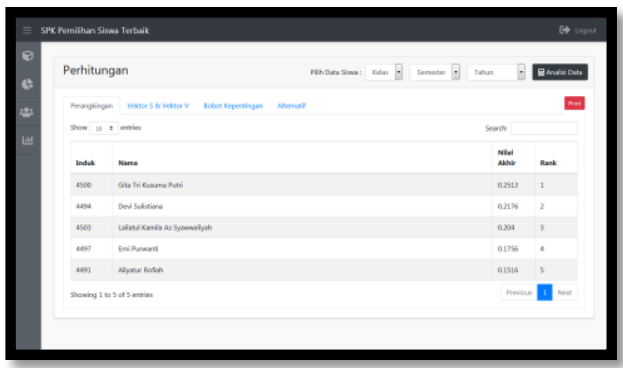

Gambar 4.4 Halaman Normalisasi \& Prangkingan

\subsubsection{Halaman Laporan}

Halaman laporan berisi data hasil dari seleksi siswa yang nantinya bisa dijadikan acuan rekomendasi oleh guru untuk mengikuti perlombaan, berikut tampilan halaman laporan dapat dilihat pada Gambar 4.5

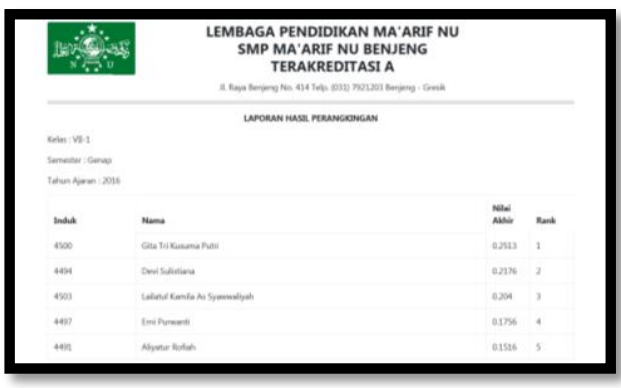

Gambar 4.5 Halaman Laporan

\section{PENUTUP}

\subsection{Kesimpulan}

Dari hasil pengujian dapat disimpulkan bahwa solusi yang diberikan oleh sistem sudah baik, dengan demikian metode WP merupakan metode yang sesuai digunakan dalam pengambilan keputusan yang melibatkan banyak kriteria. Dari hasil perhitungan sistem dan perhitungan manual dapat dikatakan sistem yang dibangun telah berjalan dengan benar yaitu untuk memberikan rekomendasi kepada guru dalam pengambilan keputusan pemilihan siswa terbaik di SMP Ma'arif NU Benjeng 
INDEXIA: Informatic and Computational Intelegent Journal

Slamet Budiono

Sistem Pendukung Keputusan Pemilihan Siswa Terbaik Menggunakan Metode Wp (Weighted Product) Studi Kasus Di Smp Ma'arif Nu Benjeng

untuk direkomendasikan dalam mengikuti perlombaan.

\subsection{Saran}

Sistem yang dibuat masih bisa dikembangkan lebih lanjut untuk mencapai tahap yang lebih sempurna dan dengan kinerja sistem yang lebih baik. Adapun saran untuk pengembangan sistem ini lebih lanjut adalah sebagai berikut :

1. Peneliti bisa menggunakan metode selain metode WP (Weighted Product ) sebagai perbandingan yang mungkin bisa menghasilkan tingkat akurasi yang lebih baik misalkan metode SAW (Simple Additive Weighting), AHP (Analytic Hierarchy Process), TOPSIS (Technique for Order Preference by Similarity to Ideal Solution).

2. Lebih baik ditambahkan akses halaman untuk user siswa yang mengikuti seleksi agar dapat mengetahui seluruh proses penilaian secara transparan.

\section{DAFTAR PUSTAKA}

[1] Ummu Ni'Matullilah. 2011. Sistem Pendukung Keputusan Penentuan Lokasi Pertokoan Yang Strategis Menggunakan Metode WP (Weighted Product). Universitas Muhammadiyah Gesik.

[2] Arifin 2000. Definisi Murid. Jakarta: Kompas, 2001

[3] Sarwono 2007. Metodologi Dan Aplikasi Riset Pendidikan. Bandumg: Pustaka Cendikia Utama
[4] Fitriyati. 2011. Sistem Pendukung Keputusan Dengan Menggunakan Metode SAW (Simple Additive Weighting) ) Untuk Pemilihan Siswa Berprestasi. Universitas Muhammadiyah Gesik.

[5] Kusrini 2007. Sistem Pendukung Keputusan

[6] Gagne (1985:40). Pengertia Dan Faktor Yang Mempengaruhi Prestasi Belajar Siswa

[7] Daihani, Dandan Umar. 2001. Komputerisasi pengambilan keputusan , Elexmedia Komputindo.

[8] Kusumadewi, Sri., Purnomo, Hari. 2004. Aplikasi Logika Fuzzy untuk Pendukung Keputusan. Yogyakarta : Graha Ilmu.

[9] Yakub, (2012). Pengantar Sistem Informasi. Yogyakarta. Graha Ilmu. 